\title{
Sinus Node Rhythm and Arrhythmia ECG Assessment
}

National Cancer Institute

\section{Source}

National Cancer Institute. Sinus Node Rhythm and Arrhythmia ECG Assessment. NCI

Thesaurus. Code C111312.

An electrocardiographic assessment of the typical and atypical cardiac rhythms

originating from the sinoatrial node. 